\title{
Performance Persistence of Equity Funds in Hungary
}

\author{
Dariusz Filip ${ }^{1}$
}

ABSTRACT This study examines the phenomenon of performance persistence of equity funds in Hungary in two time perspectives: 1-year and 6-month perspectives. The empirical results confirm the occurrence of performance dependence in consecutive periods. There is also a strong evidence of short-term persistence in the total horizon of the study (from the beginning of 2000 to the end of 2009), and in several sub-periods. The 1-year persistence was also found in the tested sample and, in general, depended on the measure applied. Furthermore, I observed performance reversal, which can be partly explained by trend changes in the financial markets. The persistence of equity funds performance in Hungary is shaped by market factors rather than the diversity of managerial characteristics.

Key words: performance persistence, mutual funds, trends on Hungarian financial markets

\section{JEL Classification: G11, G23, G29}

'ARMA in Warsaw, Direct Payments Department, Poland

\section{Introduction}

Performance persistence refers to a tendency of an organisation to obtain similar results in consecutive periods. Finance literature specifies two types of this tendency: winning persistence which occurs when organisations repeat good results, while its opposite - losing persistence - means achieving bad results in subsequent periods. Performance reversal is a specific type of return dependence and it consists in being a winner after losing or a loser after winning in performance distribution.

The empirical research on the issue of performance persistence of mutual funds is important to the managers of collective investment companies as well as investors for several reasons. First of all, the investors may treat performance persistence as a key factor for investment decisions. Secondly, the research on performance persistence helps to evaluate the efficiency of organisational solutions and human resources policy

Corespondence concerning to this article should be addressed to: dariuszfilip@tlen.pl applied by the mutual funds. Thirdly, the analysis of mutual funds performance could reveal the causes leading to the occurrence of performance persistence, which in turn may be explained by market tendencies or valuable and diverse skills of fund managers.

The main aim of this paper is to examine if the phenomenon of performance persistence of equity funds in Hungary exists. The study will also verify the hypothesis about the occurrence of performance reversal in consecutive periods. Furthermore, the author will make an attempt to indirectly identify the causes of winning or losing persistence of mutual funds. Two explications will be taken into consideration: the first refers to the skills of the managers, while the second assumes the existence of common investment strategies in funds sub-groups .

The present article consists of five sections. Section 1 contains a brief overview of existing empirical studies on performance persistence. Section 2 discusses research methodology and data characteristics. Section 3 presents the obtained empirical results. This is followed by the summary of major findings. 

the 10-year period from January 2000 to December 2009. The data were supplied by the Association of Investment Fund and Asset Management Companies in Hungary (BAMOSZ) and cover the entities classified according to investment policy as equity funds and equity-weighted funds. Since BAMOSZ does not publish the data concerning non-existent funds, the obtained sample is not free from survivorship bias. Consequently, the empirical results may be distorted. According to the literature on the subject, due to this kind of distortion, the stronger-than-actual performance persistence is observed in the large samples (cf. Brown et al., 1992).

The daily net assets values of mutual funds were recalculated to the monthly data. The data prepared in this way were compared to the historical values of the
Budapest Stock Index (BUX) in two out of three measures. The information on the index was taken from the Magyar Nemzeti Bank webpage. In order to examine performance persistence using the data mentioned above, I decided to analyse fund returns in 1-year or 6-month periods, just as Collinet \& Firer did (2003). Because of a relatively short total horizon of the study, longer comparative periods also mentioned in the literature, were ignored. The total number of mutual funds in this study may not coincide with their number at the end of each calendar year. That is to say, the number of funds included in the present study (see Table 1) can be less than the number of active funds given in periodical reports of BAMOSZ or the European Fund and Asset Management Association (EFAMA).

Table 1. Number of equity funds in Hungary included in the study

\begin{tabular}{|l|l|l|l|l|l|l|l|l|l|l|}
\hline Years & $\mathbf{2 0 0 0}$ & $\mathbf{2 0 0 1}$ & $\mathbf{2 0 0 2}$ & $\mathbf{2 0 0 3}$ & $\mathbf{2 0 0 4}$ & $\mathbf{2 0 0 5}$ & $\mathbf{2 0 0 6}$ & $\mathbf{2 0 0 7}$ & $\mathbf{2 0 0 8}$ & 2009 \\
\hline $\begin{array}{l}\text { Number of equity } \\
\text { funds }\end{array}$ & 22 & 25 & 28 & 31 & 32 & 34 & 36 & 39 & 49 & 65 \\
\hline
\end{tabular}

\section{Measurement of returns.}

In this study, I used several measures of returns based on the values of units share. The first one, the rate of return, shows the return divided by the value of the initial investment and it is calculated as follows (Mayo, 1997):

$Y_{t, i}=\frac{N A V_{t, i}-N A V_{t-1, i}}{N A V_{t-1, i}}$

where $Y_{t, i}$ is the rate of return of the fund $i$ in the period $t, N A V_{t \boldsymbol{t} t-1, i}$ is the net asset values per unit share of the fund $i$ at the end and beginning of the analysed period. The rates of return are calculated for 1-year and 6-month periods. We have to remember that this performance measure ignores the differences in the level of risk undertaken by funds.

These differences, which may be measured by a standard deviation, are taken into consideration by the Sharpe index, which is calculated according to the following formula (Sharpe, 1994):

$\operatorname{ShI} I_{t, i}=\frac{Y_{t, i}^{u}-r_{f}}{S\left(Y_{t, i}\right)}$ where $S h I_{t, i}$ is the Sharpe index on fund $i$ in the period $t, Y_{t, i}^{u}$ is the mean monthly rate of return achieved over the period $t$ by fund $i, r_{f}$ is the mean risk-free return over the same period, $S\left(Y_{t, i}\right)$ is the standard deviation of the monthly rate of return on fund $i$ in the period $t$. The Sharpe indices are calculated for the same periods as the rates of return. In case of this measure of return, the 6-month return measures calculated on the basis of six observations should be treated very carefully.

The regression intercept of the managed portfolio (3) can be viewed as a performance measure, which confronts the achieved rate of return with the expected returns and takes into account the adjusted market risk. Hence, I estimated the model for each mutual fund from the database as follows (cf. Jensen, 1968):

$Y_{t}-r_{f}=\mathrm{a}+\mathrm{b}\left(Y_{R, t}-r_{f}\right)+\mathrm{e}_{t}$

where: $Y_{t}$ is the rate of fund return in the period $t, \alpha$ (the so-called Jensen's alpha) is the measure of out- or under-performance relating to the applied benchmark, $Y_{R, t}$ is the return on the local equity market benchmark in the period $t$, the risk-free return $r_{f}$ is 
the weighted average yield on 90-day Treasury bills sold at auctions (Mayo, 1997). The local equity market benchmark used in this study was the Budapest Stock Exchange Index (BUX). The Jensen's alphas were computed only for the 1-year horizon.

\section{Methodological approach.}

The present study adopts the following research methods discussed in the literature on performance persistence: 1) the non-parametric tests; 2) the stochastic kernel estimation; 3 ) regression analysis for percentile rankings; and 4) the tests for means and medians and the investment simulation in the evaluation period for the mutual funds classified as winners and losers in the preceding period.

Non-parametric tests based on the contingency tables are the most popular methods of analysing performance persistence. In order to use them, it is essential to classify the funds as winners or losers in a given time period. What is taken into consideration is the number of successful funds in two consecutive periods (WW), unsuccessful funds in both analysed periods (LL), were winners and then losers (WL) or losers and then winners (LW). The applied criterion of classification was the median of analysed return measure in a given period.

The contingency tables make it possible to conduct two non-parametric tests of the null hypothesis, stating that the performance in the first period is unrelated to the performance in the next period. For example, this approach was adopted by Brown \& Goetzmann (1995), Agarwal \& Naik (2000) and Jackowicz (2008).

The first of the applied tests of performance persistence is based on the Cross-Product Ratio (CPR) and calculated as follows (Brown \& Goetzmann, 1995):

$C P R=\frac{W * L}{W * W}$

As can be easily demonstrated, the null hypothesis about the lack of performance persistence corresponds to the CPR equal to one. A ratio greater than one suggests the occurrence of performance persistence (predominance of the WW or LL groups) and a ratio of less than one indicates a tendency towards performance reversal (predominance of the WL or LW groups).

The standard error of the CPR natural logarithm, which is given as follows (cf. Goetzmann \& Ibbotson, 1994):
$\mathrm{S}_{\mathrm{h} C P R}=\sqrt{\frac{1}{\boldsymbol{W}}+\frac{1}{W}+\frac{1}{W}+\frac{1}{L}}$

allows us to determine the value of the test Z-statistic (Hallahan, 1999):

$$
Z=\frac{\mathrm{h} C P R}{\mathrm{~s}_{\mathrm{h} C P R}}
$$

where $\mathrm{Z}$ is asymptotically normally distributed.

The second test, which is used to measure the independence of returns, is also based on the contingency tables. Moreover, it is a simplified version of chi-square test. In the present study, I used the chi-statistic and it is calculated as follows (Tonks, 2005):

$$
\begin{aligned}
& C H I=\frac{(W W-N / 4)^{2}+(W L-N / 4)^{2}+}{N / 4} \\
& \frac{+(L W-N / 4)^{2}+(L L-N / 4)^{2}}{N / 4}
\end{aligned}
$$

where $\mathrm{N}$ is the number of funds operating in two consecutive periods. The chi-statistic follows the asymptotic chi-square distribution with one degree of freedom. The null hypothesis can be rejected when the calculated value of chi is higher than the critical value for the one degree of freedom and the adequate significance level.

Among the methods that do not require discretisation process, i.e. the process of transforming continuous variables into discrete variables, I chose the stochastic kernel estimation that is still rarely applied in the finance literature. The main reason for using non-discretisation-based methods was to protect the informational context of data value; otherwise, a part of the information included in the data set might have been lost. Moreover, the application of the stochastic kernel estimation for testing performance persistence expands the catalogue of research procedures. The application of this method in economic sciences is discussed by Durlauf \& Quah (1998).

The stochastic kernel can be defined as a graphical representation of the transition matrices with an infinite number of rows and columns, and thus, with an infinite number of states of the analysed stochastic process (cf. Epstein et al., 2000). To be more precise, we can say that the stochastic kernel is determined by the density function of the conditional probability distribution for the stochastic process in two consecutive 
periods. The stochastic kernel function is estimated by the separate estimation of the density function for the probability distribution of the two-dimensional random variable $(X(t), X(t+1))$ and the probability distribution of a random variable $X(t)$. Consequently, the estimator of the density function $f(x(t+1) \mid x(t))$ may be presented as follows (Jackowicz and Kozłowski, 2008):

$\hat{f}(x(t+1) \mid x(t))=\hat{g}(x(t), x(t+1)) / \hat{h}(x(t)) \quad(8)$,

where $\hat{g}$ is the estimator of the density function of the variable $(X(t), X(t+1))$, and $\hat{h}$ stands for the estimator of density function of the variable $X(t)$.

I decided to use the kernel estimator proposed by Hyndman et al. (1996) in order to avoid the possibility of reducing the degree of precision:

$$
\begin{aligned}
& \hat{g}(x(t), x(t+1))= \\
& =\frac{1}{n a b} \sum_{i=1}^{n} K_{2}\left[\left(\frac{\left|x(t)-x_{i}(t)\right|}{a}\right)\left(\frac{\left|x(t+1)-x_{i}(t+1)\right|}{b}\right)\right]_{(9),} \\
& \hat{h}(x(t))=\frac{1}{n a} \sum_{i=1}^{n} K_{1}\left(\frac{\left|x(t)-x_{i}(t)\right|}{a}\right)
\end{aligned}
$$

where $K_{2}$ is the function of the two-dimensional kernel (density function of a two-dimensional transition probability), $K_{1}$ is the function of a one-dimensional kernel (density function of one-dimensional transition probability), $a$ and $b$ are smoothing parameters.

In order to provide a full graphic representation of the values of the stochastic kernel, we would need a three-dimensional space. A two-dimensional representation applied in this study seems much more perspicuous in terms of interpretation. The interpretation procedure for the stochastic kernel two-dimensional mapping needs to be explained. The $\mathrm{x}$-axis and $\mathrm{y}$ axis present the values of mutual fund performance reported in the periods $t$ and $t+s$. The main figure on the graphic representation is a ridge of the stochastic kernel. We should also notice its position in relation to the straight line inclined at an angle of 45 degrees to the $\mathrm{x}$-axis. If the stochastic kernel is placed along this line, there is no change in group affiliation, which in turn means the occurrence of performance persistence. The clockwise rotation of the stochastic kernel ridge proves the increase of the significance of winning and losing persistence. A strong anticlockwise rotation of the kernel in relation to the line inclined at an angle of 45 degrees to the $\mathrm{x}$-axis implies a performance reversal tendency in consecutive periods (cf. Jackowicz \& Kozłowski, 2008).

The number of observations has to be relatively high to keep a satisfactory degree of precision in the kernel estimation process (Kulczycki, 2008). Therefore, I will be able to provide the two-dimensional mapping of the stochastic kernels only for the observations of the whole period under study.

Another research method adopted in this study refers to parametric tests. The parametric statistics allow potential inferences about the parameters of the distribution in a population. The parametric methods can often provide more accurate and precise estimates than non-parametric tests. From among the tests mentioned above, I chose the percentile ranks regression analysis (see e.g. Hallahan, 1999). Collinet \& Firer (2003) suggested the regression of percentile ranks as a means of testing performance persistence.

A percentile ranking shows a relative position of a fund in performance distribution in a given period. It is calculated from the following formula (Jackowicz \& Filip, 2009):

$$
P R_{t, i}=\frac{M P_{t, i}-M P_{\min , t}}{M P_{\max , t}-M P_{\min , t}}
$$

where $P R_{t, i}$ means the percentile ranking of the fund $i$ in the period $t, M P_{t, i}$ means the value of the relative performance for fund $i$ in the period $t, M P_{\max , t}$ means the maximum value of the relative performance in the period $t, M P_{\min , t}$ is the minimum value of the relative performance in the period $t$. In order to check the performance dependence in consecutive periods, I need to estimate the regression model:

$$
P R_{t, i}=c+d P R_{t-1, i}+\mathrm{e}_{i}
$$

where $P R_{t-1, i}$ means the percentile ranking of the fund $\mathrm{i}$ in the period $t-1$, and the parameter $d$ is a regression slope.

In this case, the null hypothesis corresponds to the value $d=0$. The occurrence of performance persistence is suggested by the statistically significant positive coefficient $d$. When it is significantly negative, it suggests performance reversal (Collinet \& Firer, 2003). 



\section{The 1-year persistence.}

The results of the research on persistence performance of mutual funds will be shown for the rates of return and the Sharpe index, while the results obtained through the Jensen's alphas will be discussed separately.

The results of non-parametric tests presented in Table 2 suggest that the yearly rates of return of equity funds in Hungary persist during the whole period under study. It was confirmed by the values of $Z$ - and chi-statistics, which make it possible to reject the null hypothesis for the significance level of $5 \%$. Strong performance persistence of mutual funds was found in four out of nine subperiods. In the last two sub-periods, I observed a statistically significant performance reversal.
After changing the measure of performance into the Sharpe index, the non-parametric tests based on contingency tables provided the evidence of performance persistence existing only in one sub-period (which took place in 2007). In the last sub-period, I observed a performance reversal at the significance level of $10 \%$. Having used the Sharpe index as a measure of performance, I found out that the phenomenon of winning and losing persistence is absent from the rest of sub-periods and from the total analysed horizon. The finding, which is contrary to the previous results, will be verified through the application of the remaining methods.

Table 2. Results of non-parametric tests based on contingency tables in 1-year horizon

\begin{tabular}{|c|c|c|c|c|c|c|c|c|c|c|c|c|}
\hline Measure & \multicolumn{6}{|c|}{ Rate of Return } & \multicolumn{6}{|c|}{ Sharpe Index } \\
\hline \multirow{2}{*}{ Periods } & \multirow{2}{*}{ WW } & \multirow{2}{*}{ LL } & \multirow{2}{*}{ WL } & \multirow{2}{*}{ LW } & \multicolumn{2}{|c|}{ Statistic } & \multirow{2}{*}{ WW } & \multirow{2}{*}{$\mathrm{LL}$} & \multirow{2}{*}{$\mathrm{WL}$} & \multirow{2}{*}{ LW } & \multicolumn{2}{|c|}{ Statistic } \\
\hline & & & & & Z & $\mathrm{CHI}$ & & & & & Z & $\mathrm{CHI}$ \\
\hline $2001 / 2000$ & 6 & 5 & 5 & 6 & 0.0000 & 0.1818 & 5 & 4 & 6 & 7 & -0.8513 & 0.9091 \\
\hline $2002 / 2001$ & 10 & 10 & 3 & 2 & $* * * 2.7677$ & $* * * 9.0800$ & 8 & 8 & 5 & 4 & 1.3902 & 2.0400 \\
\hline $2003 / 2002$ & 6 & 6 & 8 & 8 & -0.7533 & 0.5714 & 7 & 7 & 7 & 7 & 0.0000 & 0.0000 \\
\hline $2004 / 2003$ & 7 & 7 & 9 & 8 & -0.5328 & 0.3548 & 7 & 7 & 9 & 8 & -0.5328 & 0.3548 \\
\hline $2005 / 2004$ & 14 & 15 & 2 & 1 & $* * * 3.6362$ & $* * * 21.2500$ & 8 & 7 & 8 & 9 & -0.3540 & 0.2500 \\
\hline 2006/2005 & 14 & 14 & 3 & 3 & $* * * 3.4242$ & $* * * 14.2353$ & 9 & 9 & 8 & 8 & 0.3428 & 0.1176 \\
\hline $2007 / 2006$ & 13 & 13 & 5 & 5 & $* * 2.5679$ & $* * * 7.1111$ & 13 & 13 & 5 & 5 & $* * * 2.5679$ & $* * * 7.1111$ \\
\hline 2008/2007 & 6 & 5 & 13 & 13 & $* *-2.3961$ & **6.1351 & 8 & 8 & 11 & 10 & -0.8156 & 0.7297 \\
\hline 2009/2008 & 6 & 9 & 18 & 15 & $* *-2.5447$ & $* * * 7.5000$ & 8 & 10 & 16 & 14 & $*_{-1.7186}$ & *3.3333 \\
\hline $\begin{array}{l}\text { Total horizon: } \\
\text { 2009-2000 }\end{array}$ & 82 & 84 & 66 & 61 & $* * 2.2765$ & $*$ *5.3891 & 73 & 73 & 75 & 72 & -0.0566 & 0.0648 \\
\hline
\end{tabular}

Note: ${ }^{* *},{ }^{* * *}$ indicate the grounds to reject the null hypothesis at the respective levels of significance: $10 \%, 5 \%$ and $1 \%$.

The results of the stochastic kernel estimation based on the rates of return from the years 2000 to 2009 are given in Fig. 2. They confirm the occurrence of performance persistence of equity funds in Hungary. The ridge of the stochastic kernel is arranged along the straight line inclined at an angle of 45 degrees to the $\mathrm{x}$-axis. I also observe a deformation of the lower part of the space mentioned above, which may suggest the performance reversal of a group of mutual funds in some periods, since the ridge of the kernel in that part of the figure is rotated anticlockwise in relation to the described line.

The mapping of the stochastic kernel for the Sharpe index confirms the conclusion about the dependence of fund performance in successive periods. As presented in the Fig. 1, the main ridge of the stochastic kernel is partly situated along the straight line inclined at an angle of 45 degrees to the $\mathrm{x}$-axis and also rotated anticlockwise in relation to the mentioned line. Furthermore, I can observe several parts of the ridge of the 
stochastic kernel for the applied performance measure. One may also observe a noticeable polarisation of the
Sharpe indices, which is higher in consecutive periods than in the case of 1-year rates of return.

Figure 1. Stochastic kernel mapping for the mutual fund performance: 1-year rate of return and 1-year Sharpe index

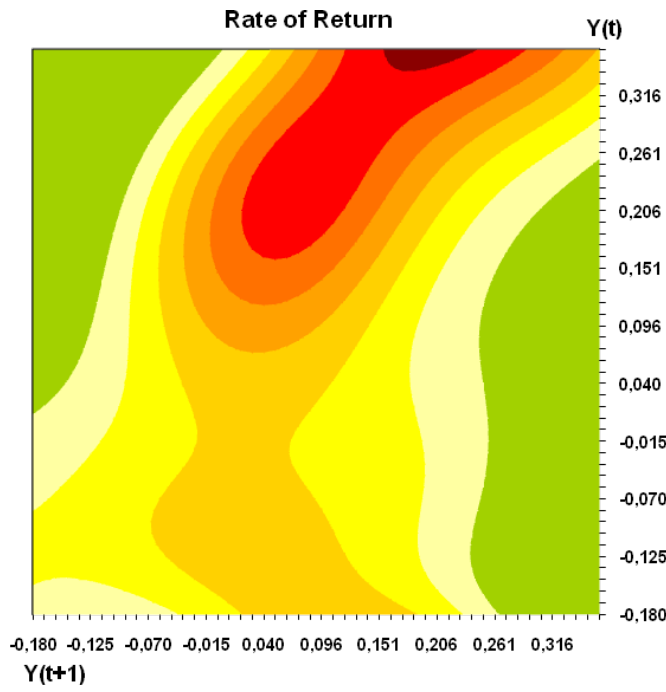

The results of parametric tests conducted after estimating the regression of percentile ranks models are presented in Table 3 and show that the percentile ranks for the rates of return in the previous sub-period have significant and positive influence on the position of funds in four out of nine sub-periods and also in the total horizon. The null hypothesis about the value $\mathrm{d}=0$ in the mentioned periods may be rejected at the significance level of $1 \%$. It is also important to stress the occurrence of performance reversal in 2001 and 2009. The values of determination coefficients $\left(\mathrm{R}^{2}\right)$ run from $21 \%$ to $65 \%$ in the sub-periods, for which the parameter $\mathrm{d}$ was statistically significant.

The number of sub-periods, for which the position of funds calculated from the Sharpe index significantly influences the position of a fund in the next period, is considerably lower than as mentioned above. As can be concluded from Table 3, the estimated models of percentile ranks regression allow for the rejection of the null hypothesis in 2001, 2002 and 2007. This is possible at the respective levels of significance of 10\%, 5\% and $1 \%$. It also has to be noticed that I observed performance reversal in the first sub-period (2001/2000).

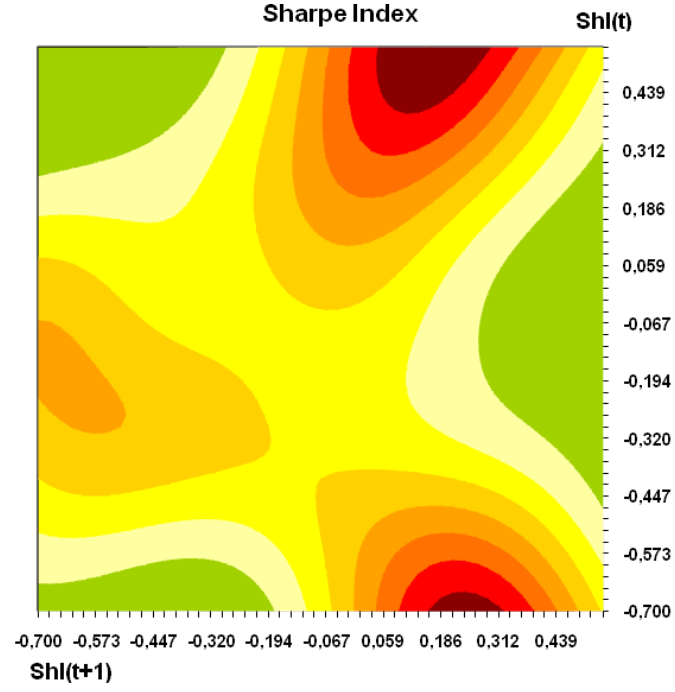

The percentile ranks for the Sharpe index in the previous periods considerably influence the ranks in the following periods at the level of significance, which amounts to $10 \%$ in the total horizon.

The results obtained through the application of the research method of distinguishing the classification and the evaluation periods for analysing 1-year returns of equity funds in Hungary were presented in Table 4. It contains the means of the rate of return in evaluation periods for the two groups of funds (winners and losers), the results of the t-test for means, the results of the Tukey-Duckworth test for medians in the mentioned groups and information about the consequences of investment in the unit shares of funds, which were classified as winners and losers in the classification period.

The results of the tests for the difference in the mean and median values of rates of return in the mentioned groups once again show that the strongest support for the alternative hypothesis was found in the years 2002, 2005-2007 and 2009. The rejection of the hypothesis about the equal value of means and medians was possible at the significance level of $5 \%$ and $1 \%$. This conclusion may be further confirmed by examining the 
consequences of investment in these unit shares of funds, which were winners in the past. The results of investment simulation would amount from 100 EUR to 225 EUR in the mentioned years. In the last subperiod, where I observed performance reversal using the t-test for means, an investment loss amounted to over 150 EUR.

The next stage of this study consists in examining performance persistence in the 1-year horizon by means of Jensen's alphas. As it turned out, over $81 \%$ of the esti-

Table 3. The models of percentile ranks regression calculated from the rate of return and the Sharpe index in 1-year horizon

\begin{tabular}{|l|c|c|c|c|c|c|}
\hline \multirow{2}{*}{ Measure } & \multicolumn{3}{|c|}{ Rate of Return } & \multicolumn{3}{c|}{ Sharpe Index } \\
\hline \multirow{2}{*}{ Periods } & \multicolumn{3}{|c|}{ Coefficients } & \multicolumn{3}{c|}{ Coefficients } \\
\hline $2001 / 2000$ & $d$ & $t$-value & $R^{2}$ & $d$ & t-value & $R^{2}$ \\
\hline $2002 / 2001$ & -0.5310 & $* *-2.3057$ & 0.2100 & -0.5154 & $*-1.7540$ & 0.1333 \\
\hline $2003 / 2002$ & 0.7815 & $* * * 4.0966$ & 0.4218 & 0.4968 & $* * 2.5522$ & 0.2207 \\
\hline $2004 / 2003$ & 0.0067 & 0.0395 & 0.0001 & 0.0023 & 0.0148 & 0.0000 \\
\hline $2005 / 2004$ & 0.1218 & 0.6577 & 0.0147 & 0.0598 & 0.2631 & 0.0024 \\
\hline $2006 / 2005$ & 0.7534 & $* * * 7.4301$ & 0.6479 & -0.1127 & -0.8477 & 0.0234 \\
\hline $2007 / 2006$ & 0.4632 & $* * * 4.5762$ & 0.3956 & 0.0133 & 0.3169 & 0.0031 \\
\hline $2008 / 2007$ & 0.3817 & $* * * 3.1448$ & 0.2253 & 0.9316 & $* * * 15.7996$ & 0.8801 \\
\hline $2009 / 2008$ & -0.2365 & -1.0051 & 0.0281 & -0.0612 & -0.5006 & 0.0071 \\
\hline Total horizon: & -0.3284 & $* * *-4.0867$ & 0.2664 & -0.3480 & -1.3947 & 0.0406 \\
\hline $2009-2000$ & 0.2193 & $* * * 3.9210$ & 0.0502 & 0.0964 & $* 1.6839$ & 0.0096 \\
\hline
\end{tabular}

Note: ${ }^{*}{ }^{* *},{ }^{* *}$ indicate the grounds to reject the null hypothesis at the respective significance levels of $10 \%, 5 \%$ and $1 \%$.

Table 4. The results of mutual funds qualified to winner and loser groups in the evaluation period (1-year horizon)

\begin{tabular}{|c|c|c|c|c|c|}
\hline \multirow[b]{2}{*}{ Periods } & \multicolumn{2}{|c|}{$\begin{array}{c}\text { Mean value of rate of return in evalua- } \\
\text { tion period }\end{array}$} & \multirow[b]{2}{*}{ t-test for means } & \multirow{2}{*}{$\begin{array}{l}\text { TD-test for me- } \\
\text { dians }\end{array}$} & \multirow{2}{*}{$\begin{array}{l}\text { The simulation } \\
\text { result (the final } \\
\text { value of } 1000 \text { EUR } \\
\text { capital invested } \\
\text { proportionally } \\
\text { into winners and } \\
\text { losers) }\end{array}$} \\
\hline & $\begin{array}{c}\text { Among winners in } \\
\text { the classification } \\
\text { period }\end{array}$ & $\begin{array}{c}\text { Among losers in } \\
\text { the classification } \\
\text { period }\end{array}$ & & & \\
\hline $2001 / 2000$ & -0.1353 & -0.1164 & -0.6747 & 4 & -18.88 \\
\hline $2002 / 2001$ & -0.0073 & -0.2329 & $* * * 4.6873$ & $* * 9$ & 225.61 \\
\hline $2003 / 2002$ & 0.1494 & 0.1563 & -0.2825 & $\mathrm{bpz}$ & -6.95 \\
\hline $2004 / 2003$ & 0.1734 & 0.1633 & 0.1407 & $* * 7$ & 10.09 \\
\hline $2005 / 2004$ & 0.3394 & 0.2176 & $* * * 6.7817$ & $* * * 20$ & 121.85 \\
\hline $2006 / 2005$ & 0.1897 & 0.0902 & $* * * 4.5798$ & $* * * 11$ & 99.57 \\
\hline 2007/2006 & 0.0637 & 0.0102 & $* * 2.5104$ & bpz & 53.53 \\
\hline 2008/2007 & -0.4216 & -0.3764 & -1.6610 & 2 & -45.22 \\
\hline 2009/2008 & 0.2785 & 0.4310 & $* * *-3.2865$ & bpz & -152.47 \\
\hline
\end{tabular}

Notes: ${ }^{* * *},{ }^{* *}$ indicate the grounds to reject the null hypothesis at the respective significance levels of $10 \%, 5 \%$ and $1 \%$. bpz symbol informs that the assumptions of the Tukey-Duckworth test were not met. 
mated alphas were statistically insignificant. In this case, I did not take them into account as far as performance persistence or reversal are concerned. Accordingly, it will not be possible to discuss one of the possible causes of the occurrence of performance persistence, i.e. the skills of fund managers. In this and other regards, Jensen's measures would have been useful.

This part of investigation into the performance of equity funds in Hungary produced strong evidence for the occurrence of performance persistence in the 1-year horizon (even though in certain cases, the evidence was sometimes unstable in relation to the applied measures). Such a conclusion could be interesting for investors with regard to their investment decisions. The good returns achieved by a given fund in a previous period indicate, in most cases, its relatively favourable performance in a following period in relation to other funds. However, all the tests confirmed the statistical significance of performance reversal. The reversals took place especially in the last two sub-periods. The rates of return and the Sharpe indices used interchangeably only partly confirmed the results obtained mutually. The grounds to reject the hypothesis about the independence of fund performance in consecutive periods are weaker for the Sharpe index, especially in non-parametric tests. In general, the strength of the evidence for the occurrence of performance persistence of equity funds in Hungary de- pends on the measure of return used. One of the reasons of this situation may be the state of data, which is incomplete. As for this particular sample, we have to remember that it contains survivorship bias, i.e. non-surviving funds were excluded from the data set. However, it must be noticed that the number of mutual funds under investigation is still quite representative.

The performance persistence of equity funds in Hungary could be partly correlated with the situation on the capital market. The values of BUX index presented in Fig. 2 show the main trends in the Budapest Stock Exchange (BSE). A downward tendency occurred in the first two years of investigation, stagnation took place in the years 2002-2004, and a well-defined upward trend was observed from the year 2004 to the first half of 2007. This situation was reflected in the performance of mutual funds. The three market terms mentioned above roughly correspond with the periods, in which an insignificant performance reversal, performance independence in consecutive sub-periods and quite strong persistence were observed. The following periods (from the second half of 2007 to the end of 2008 and from 2009 to the end of the study horizon), could be described as the dynamic changes of trends in financial markets. They corresponded with the reversal in funds performance. Finally, the relationship between persistence and market factors will be discussed in the following section of this article.

Figure 2. The values of BUX index from January 2000 to December 2009

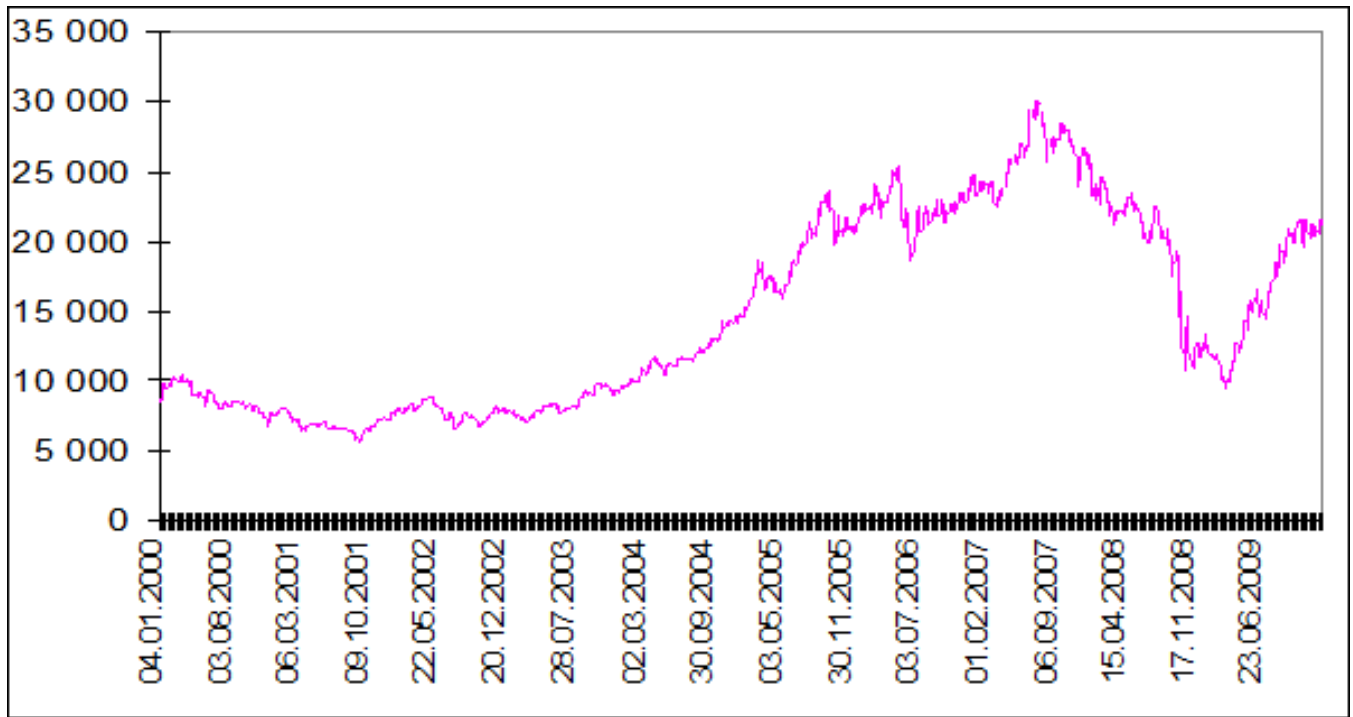


The 6-month persistence. The investigation into persistence in the 6-month horizon will also start from the contingency tables, based on which I obtained the values of Z- and chi-statistics for rates of return and Sharpe indices. As we can see in Table 5, the occurrence of performance persistence may be observed in the total horizon (from the first half of 2000 to the second half of 2009). In ten out of nineteen sub-periods, we can notice the grounds to reject the null hypothesis about the independence of equity fund performance in consecutive sub-periods, as measured by means of the rates of return. In eight of them, the rejection of the null hypothesis was possible at the significance level of $1 \%$. Furthermore, the statistical significant performance reversal was detected four times. From the first half of 2004 to the first half of 2005, only one fund changed its fund group affinity. Hence, the Zstatistic could not be calculated. Finally, the application of this measure of return has confirmed the premises about the occurrence of short-term performance persistence.
The results of non-parametric tests for the Sharpe index are equally strong. The interrelations existing between the performance of mutual funds are statistically significant in ten out of nineteen sub-periods. In the second half of 2002 and the second half of 2004, there is hardly any record of changes in funds' group affinity. Nonetheless, three sub-periods demonstrated performance reversal at different levels of significance. It should be mentioned that the 6-month periods of the occurrence of performance reversal for the Sharpe indices are identical as for the rates of return. The absolute values of $\mathrm{Z}$ - and chi-statistics calculated for the Sharpe index are lower than values of the test statistics for the rates of return in the remaining investigated sub-periods. However, they provide strong evidence, which allow for the rejection of the null hypothesis about the independence of equity fund performance in consecutive periods. In such a case, the high values of the test statistics are not surprising.

Table 5. Results of non-parametric tests based on contingency tables in the 6-month horizon

\begin{tabular}{|c|c|c|c|c|c|c|c|c|c|c|c|c|}
\hline Measure & & & & Ratec & Return & & & & & Shar & Index & \\
\hline & & & & & Stat & stic & & & & & Stat & tic \\
\hline Periods & WW & LL & WL & LW & Z & $\mathrm{CHI}$ & WW & $\mathrm{L}$ & NL & W & Z & $\mathrm{CHI}$ \\
\hline 2nd half of 2000 / 1st half of 2000 & 6 & 4 & 5 & 7 & -0.4329 & 0.9091 & 6 & 4 & 5 & 7 & -0.4329 & 0.9091 \\
\hline 1st half of 2001 / 2nd half of 2000 & 7 & 6 & 6 & 6 & 0.1923 & 0.1200 & 5 & 4 & 8 & 8 & -1.3902 & 2.0400 \\
\hline 2nd half of 2001 / 1st half of 2001 & 4 & 4 & 9 & 8 & *-1.7531 & $3.3200^{*}$ & 3 & 3 & 10 & 9 & $* *-2.4577$ & $* * * 6.8400$ \\
\hline 1st half of 2002 / 2nd half of 2001 & 13 & 13 & 1 & 1 & $* * * 3.4954$ & $* * * 20.5714$ & 13 & 13 & 1 & 1 & $* * * 3.4954$ & $* * * 20.5714$ \\
\hline 2nd half of 2002 / 1st half of 2002 & 13 & 13 & 1 & 1 & $* * * 3.4954$ & $* * * 20.5714$ & 14 & 13 & 0 & 1 & nc & $* * * 24.2857$ \\
\hline 1st half of 2003 / 2nd half of 2002 & 4 & 3 & 11 & 11 & $* * *-2.6418$ & $* * * 7.8276$ & 3 & 2 & 12 & 12 & $* * *-3.1781$ & $* * * 12.5172$ \\
\hline 2nd half of 2003 / 1st half of 2003 & 6 & 6 & 10 & 9 & -1.2418 & 1.6452 & 7 & 7 & 9 & 8 & -0.5328 & 0.3548 \\
\hline 1st half of 2004 / 2nd half of 2003 & 12 & 12 & 4 & 4 & $* * * 2.6910$ & $* * * 8.0000$ & 11 & 11 & 5 & 5 & $* * 2.0674$ & 4.5000 \\
\hline 2 nd half of 2004 / 1st half of 2004 & 16 & 16 & 0 & 0 & nc & $* * 32.0000$ & 16 & 16 & 0 & 0 & nc & $* * 32.0000$ \\
\hline 1st half of 2005 / 2nd half of 2004 & 16 & 16 & 1 & 0 & nc & $* * 29.1818$ & 9 & 8 & 8 & 8 & 0.1689 & 0.0909 \\
\hline 2nd half of 2005 / 1st half of 2005 & 8 & 8 & 9 & 9 & -0.3428 & 0.1176 & 9 & 9 & 8 & 8 & 0.3428 & 0.1176 \\
\hline 1st half of 2006 / 2nd half of 2005 & 11 & 10 & 6 & 7 & 1.3610 & 2.0000 & 14 & 13 & 3 & 4 & $* * * 3.1788$ & $* * * 11.8824$ \\
\hline 2nd half of 2006 / 1st half of 2006 & 5 & 4 & 13 & 13 & $* * *-2.7464$ & $* * * 8.3143$ & 7 & 5 & 11 & 12 & *-1.8460 & *3.7429 \\
\hline 1st half of 2007 / 2nd half of 2006 & 17 & 17 & 2 & 2 & $* * * 4.0486$ & $* * * 23.6842$ & 16 & 16 & 3 & 3 & $* * * 3.7628$ & $* * * 17.7895$ \\
\hline 2nd half of 2007 / 1st half of 2007 & 7 & 9 & 13 & 10 & -1.1036 & 1.9231 & 12 & 14 & 8 & 5 & $* * 2.0719$ & $* * 5.0000$ \\
\hline 1st half of 2008 / 2nd half of 2007 & 12 & 14 & 10 & 8 & 1.2040 & 1.8182 & 12 & 13 & 10 & 9 & 0.9026 & 0.9091 \\
\hline 2nd half of 2008 / 1st half of 2008 & 12 & 10 & 12 & 14 & -0.5787 & 0.6667 & 13 & 11 & 12 & 12 & -0.0120 & 0.1667 \\
\hline 1st half of 2009 / 2nd half of 2008 & 11 & 11 & 19 & 18 & *-1.9294 & **3.8475 & 15 & 15 & 15 & 14 & 0.1324 & 0.0508 \\
\hline 2nd half of 2009 / 1st half of 2009 & 20 & 19 & 13 & 13 & 1.5999 & 2.6308 & 19 & 18 & 14 & 14 & 1.1111 & 1.2769 \\
\hline Total horizon: 2009-2000 & 200 & 195 & 145 & 141 & ${ }^{* * *} 4.1586$ & $* * * 17.5668$ & 204 & 195 & 142 & 140 & $* * * 4.4575$ & $* * * 20.3509$ \\
\hline
\end{tabular}

Note: ${ }^{* *},{ }^{* * *}$ indicate the grounds to reject the null hypothesis at the respective levels of significance: $10 \%, 5 \%$ and $1 \%$. The nc symbol was used because of the lack of changing groups, which did not allow the Z-statistic to be calculated. The number of mutual funds, which could be classified as the WL or LW categories, equals 0. 
The results of the stochastic kernel estimation may confirm the general results of non-parametric tests in the 6-month horizon. As shown in Fig. 3, where the rates of return were used as a performance measure, the stochastic kernel is situated along the straight line inclined at an angle of 45 degrees to the $\mathrm{x}$-axis. I did not observe any considerable deviations in the central part of the kernel ridge from the mentioned line, which is another evidence of performance persistence of equity funds in Hungary. The graphic representations of the shape of the stochastic kernel for the rates of return in the 6-month (see Fig. 3) and 1-year horizon (see Fig. 1) are not too disparate.

Moreover, the estimation of the stochastic kernel for the Sharpe indices provides an equally strong piece of evidence, which allows for the rejection of the null hypothesis about the independence of fund performance in consecutive periods. The arrangement of the kernel ridge along the diagonal derived from the first quarter of Fig. 3 is only partly similar to the stochastic kernel for the Sharpe indices in the 1-year horizon (see Fig. 1). The persistence seems stronger for the 6-month Sharpe indices. However, I observed a fragmentary performance convergence characterised by a lower deviation of the kernel. Unfortunately, it was impossible to generalise the received results probably because of the survivorship bias present in the sample. It may distort the result concerning the occurrence of the performance dependence in consecutive periods.

Figure 3. Stochastic kernel mapping for mutual fund performance: 6-month rate of return and 6-month Sharpe index

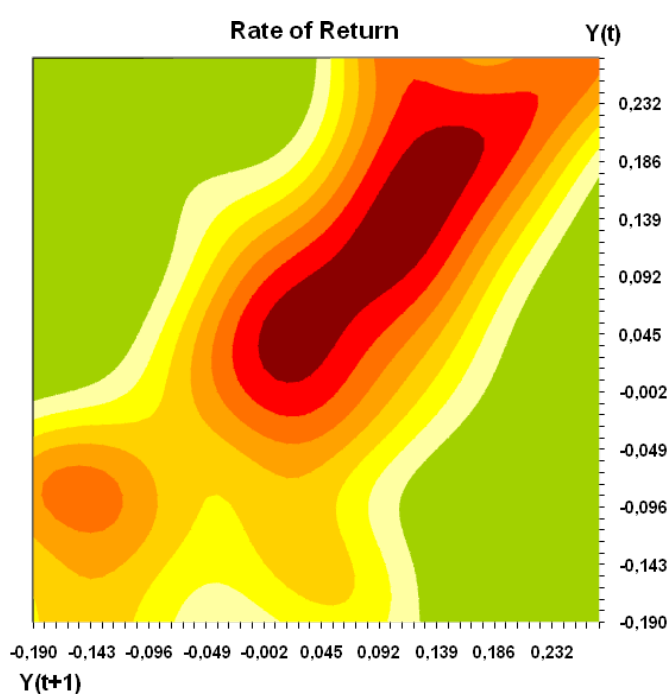

Similar conclusions about performance persistence can be drawn from the regression of percentile ranks for the 6-month rates of return (see Table 6). In eleven out of nineteen analysed sub-periods, I found a strong evidence of performance dependence of mutual funds in consecutive periods. The four of them were characterised by performance reversal at a different level of significance. The coefficients $\mathrm{R}^{2}$ oscillated from $13 \%$ to $87 \%$ in the seven remaining sub-periods with a positive and statistically significant value of the parameter d. Eventually, the null hypothesis about the indepen-

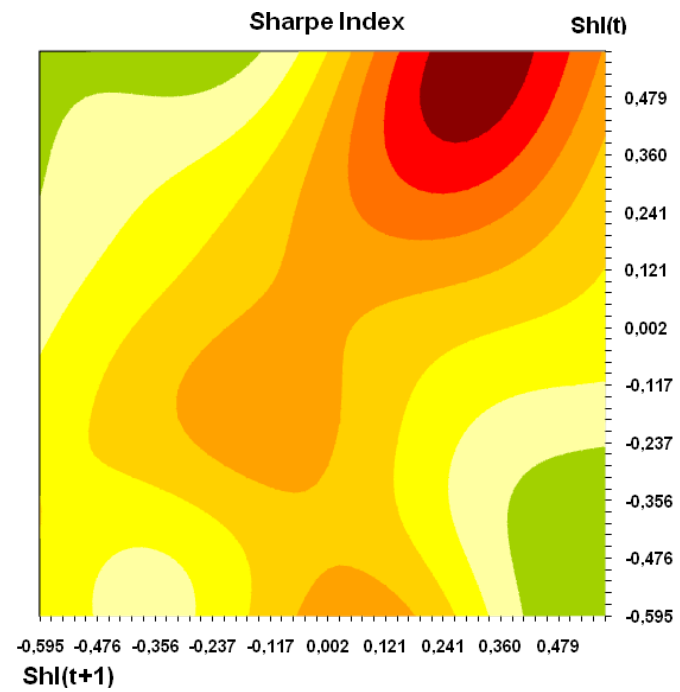

dence of percentile ranks in consecutive periods was rejected at the significance level of $1 \%$.

As we can see in Table 6, the application of the Sharpe index as a measure of performance in the test of persistence provided strong arguments for the rejection of the null hypothesis about the independence of percentile ranks in the 6-month sub-periods and in the total horizon. The six sub-periods were characterised by a positive parameter $d$ at the significance level of $1 \%$. The coefficients R2 in these sub-periods oscillated from 19\% to $83 \%$. A statistically significant performance reversal was 
observed in four sub-periods and they mostly overlap with the sub-periods of reversal in the rates of return. It should be mentioned that it is the first time in this study when the results for Sharpe indices provide stronger evidence to reject the null hypothesis than the results for rates of return. The results of the regression of percentile ranks for both the performance measures confirm the conclusions from non-parametric tests as conducted in the 6-month horizon.

Table 6. The models of percentile ranks regression calculated from the rate of return and the Sharpe index in the 6-month horizon

\begin{tabular}{|c|c|c|c|c|c|c|}
\hline Measure & \multicolumn{3}{|c|}{ Rate of Return } & \multicolumn{3}{|c|}{ Sharpe Index } \\
\hline \multirow{2}{*}{ Periods } & \multicolumn{3}{|c|}{ Coefficients } & \multicolumn{3}{|c|}{ Coefficients } \\
\hline & $d$ & t-value & $R^{2}$ & $d$ & t-value & $R^{2}$ \\
\hline 2nd half of $2000 / 1$ st half of 2000 & -0.1182 & -0.4646 & 0.0107 & 0.4467 & $* * 2.5514$ & 0,2456 \\
\hline 1st half of 2001 / 2nd half of 2000 & 0.0654 & 0.3135 & 0.0043 & -0.0704 & -0.3732 & 0,0060 \\
\hline 2nd half of 2001 / 1st half of 2001 & -0.0967 & -0.5267 & 0.0119 & -0.5376 & $* * *-3.7022$ & 0,3734 \\
\hline 1st half of 2002 / 2nd half of 2001 & 1.0789 & $* * * 8.7870$ & 0.7481 & 1.2482 & $* * 5.6029$ & 0,5470 \\
\hline 2nd half of 2002 / 1st half of 2002 & 1.1184 & $* * * 12.7281$ & 0.8617 & 0.5848 & $* * * 4.4782$ & 0,6902 \\
\hline 1st half of 2003 / 2nd half of 2002 & -0.2653 & $* *-2.1662$ & 0.1481 & -0.2974 & $* *-2.1774$ & 0,1494 \\
\hline 2nd half of 2003 / 1st half of 2003 & -0.2272 & -1.4545 & 0.0680 & -0.1632 & -0.9855 & 0,0324 \\
\hline 1st half of 2004 / 2nd half of 2003 & 0.7718 & $* * * 4.1225$ & 0.3616 & 0.6157 & $* * 2.6708$ & 0,1921 \\
\hline 2nd half of 2004 / 1st half of 2004 & 0.9907 & $* * * 14.0216$ & 0.8676 & 0.8742 & $* * * 11.9767$ & 0,8270 \\
\hline 1st half of 2005 / 2nd half of 2004 & 0.7874 & $* * * 9.0560$ & 0.7257 & -0.0109 & -0.0956 & 0,0003 \\
\hline 2nd half of 2005 / 1st half of 2005 & -0.0589 & -0.4585 & 0.0065 & 0.3128 & 1.2687 & 0,0479 \\
\hline 1st half of 2006 / 2nd half of 2005 & 0.2559 & 1.4762 & 0.0638 & 0.0196 & $* * * 2.8932$ & 0,2073 \\
\hline 2nd half of 2006 / 1st half of 2006 & -0.5426 & $* * *-2.8515$ & 0.1977 & -0.4546 & $* *-2.6458$ & 0,1750 \\
\hline 1st half of 2007 / 2nd half of 2006 & 0.6321 & ***8.5995 & 0.6788 & 0.6458 & ***7.7780 & 0,6335 \\
\hline 2nd half of 2007 / 1st half of 2007 & -0.1470 & -1.1048 & 0.0328 & 0.3143 & $* * 2.2786$ & 0,1260 \\
\hline 1st half of 2008 / 2nd half of 2007 & 0.0518 & 0.3519 & 0.0030 & 0.2905 & $* * * 3.0760$ & 0,1875 \\
\hline 2nd half of 2008 / 1st half of 2008 & -0.1822 & *-1.8411 & 0.0700 & -0.2181 & -1.6698 & 0,0583 \\
\hline 1st half of 2009 / 2nd half of 2008 & -0.5447 & $* * *-4.0801$ & 0.2260 & -0.4958 & $* * *-4.8976$ & 0,2962 \\
\hline 2nd half of 2009 / 1st half of 2009 & 0.4283 & $* * * 3.0608$ & 0.1295 & 0.2268 & *1.6902 & 0,0434 \\
\hline Total horizon: 2009-2000 & 0.2390 & $* * * 6.5371$ & 0.0595 & 0.2247 & $* * * 6.0510$ & 0,0515 \\
\hline
\end{tabular}

Note: ${ }^{*},{ }^{* * * *}$ indicate the grounds to reject the null hypothesis at the respective significance levels of 
The analysis of a concept of investing in unit shares of past winners is presented in Table 7. As the table shows, in five sub-periods, the difference resulting from investing in past winners and losers reached 10$20 \%$ of invested capital. However, the final values of the 1000 EUR capital were negative in eight cases. In six sub-periods, the results of the t-test for the mean values of the rates of return were positive and statistically significant at the level of $1 \%$. The test for the equal value of medians supplied the grounds to reject the null hypothesis six times. The strongest statistical and financial arguments in favour of trusting assets to past winners were observed in half of the horizon (second half of 2004, first half of 2005 and in the year 2002).

Table 7. The results of mutual funds qualified to winner and loser groups in the evaluation period (6-month horizon)

\begin{tabular}{|c|c|c|c|c|c|}
\hline \multirow[b]{2}{*}{ Periods } & \multicolumn{2}{|c|}{$\begin{array}{c}\text { Mean value of rate of return } \\
\text { in evaluation period }\end{array}$} & \multirow[b]{2}{*}{$\begin{array}{l}\text { t-test for } \\
\text { means }\end{array}$} & \multirow[b]{2}{*}{$\begin{array}{l}\text { TD-test for } \\
\text { medians }\end{array}$} & \multirow{2}{*}{$\begin{array}{l}\text { The simulation } \\
\text { result (the final } \\
\text { value of } 1000 \text { EUR } \\
\text { capital invested } \\
\text { proportionally into } \\
\text { winners and losers) }\end{array}$} \\
\hline & $\begin{array}{c}\text { Among } \\
\text { winners in } \\
\text { classification } \\
\text { period }\end{array}$ & $\begin{array}{c}\text { Among } \\
\text { losers in } \\
\text { classification } \\
\text { period }\end{array}$ & & & \\
\hline 2nd half of 2000 / 1st half of 2000 & -0.0606 & -0.0554 & -0.2918 & $b p z$ & -5.22 \\
\hline 1st half of 2001 / 2nd half of 2000 & -0.0990 & -0.1013 & 0.1429 & $b p z$ & 2.38 \\
\hline 2nd half of 2001 / 1st half of 2001 & -0.0432 & -0.0153 & -1.2938 & $b p z$ & -27.95 \\
\hline 1st half of 2002 / 2nd half of 2001 & 0.0219 & -0.1526 & $* * * 10.0382$ & $* * * 24$ & 174.56 \\
\hline 2nd half of 2002 / 1st half of 2002 & 0.0288 & -0.1370 & $* * * 13.2617$ & $* * * 26$ & 165.86 \\
\hline 1st half of 2003 / 2nd half of 2002 & 0.0380 & 0.0736 & *-1.9986 & $b p z$ & -35.51 \\
\hline 2nd half of 2003 / 1st half of 2003 & 0.0774 & 0.1072 & *-1.76996 & *6 & -29.82 \\
\hline 1st half of 2004 / 2nd half of 2003 & 0.1171 & 0.0442 & $* * * 2.9001$ & $b p z$ & 72.94 \\
\hline 2nd half of 2004 / 1st half of 2004 & 0.1882 & -0.0167 & $* * * 12.8306$ & $* * * 32$ & 204.86 \\
\hline 1st half of 2005 / 2nd half of 2004 & 0.2027 & 0.0930 & $* * * 9.0120$ & $* * * 31$ & 109.67 \\
\hline 2nd half of 2005 / 1st half of 2005 & 0.1161 & 0.1135 & 0.2202 & 3.0 & 2.58 \\
\hline 1st half of 2006 / 2nd half of 2005 & 0.0633 & 0.0564 & 0.5439 & 2.0 & 6.86 \\
\hline 2nd half of 2006 / 1st half of 2006 & 0.0514 & 0.1112 & $* *-2.2111$ & $b p z$ & -59.85 \\
\hline 1st half of 2007 / 2nd half of 2006 & 0.1373 & 0.0395 & $* * * 7.6488$ & $* * * 29$ & 97.77 \\
\hline 2nd half of 2007 / 1st half of 2007 & -0.0579 & -0.0352 & -1.4339 & $b p z$ & -22.74 \\
\hline 1st half of 2008 / 2nd half of 2007 & -0.1846 & -0.2075 & *1.6909 & $b p z$ & 22.91 \\
\hline 2nd half of 2008 / 1st half of 2008 & -0.2895 & -0.2384 & *-1.7990 & *5 & -51.13 \\
\hline 1st half of 2009 / 2nd half of 2008 & 0.0885 & 0.1510 & $* *-2.2386$ & *5 & -62.49 \\
\hline 2nd half of 2009 / 1st half of 2009 & 0.2601 & 0.2016 & $* * 2.6103$ & $* * * 12$ & 58.44 \\
\hline
\end{tabular}

Notes: ${ }^{* * *},{ }^{* * *}$ indicate the grounds to reject the null hypothesis at the respective significance level of 10\%,5\% and $1 \%$. The bpz symbol informs that the assumptions of the Tukey-Duckworth test were not met. 
The analysis of performance persistence of equity funds in Hungary in the 6-month horizon provides stronger arguments for the rejection of the null hypothesis about performance independence in consecutive periods than the 1-year horizon's investigation. This was confirmed by the rates of return as well as the Sharpe indices. The same conclusion may be drawn from the test results obtained within the entire horizon of the study. I observed statistically significant performance reversal in several sub-periods. Therefore, the investors may take into account the occurrence of possible performance persistence phenomena while making their investment decisions. The returns of the mutual funds that persist their performance, in turn, could be more often perceived as steady and predictive.

The internal conformity of results obtained through the application of several methods enables us to distinguish the periods characterised by the lack of performance mobility of funds. It is also possible to partly connect this lack of mobility with the situation in Hungarian financial market (see Fig. 2). I observed a statistically significant performance persistence of collective investment companies while the BSE was experiencing a moderate and stable upward trend. That situation took place from the second half of 2001 to the second half of 2002, between the first half of 2004 and the first half of 2005, and from the second half of 2006 to the first half of 2007. However, when the change in trend took place, i.e. in the second half of 2002 and the second half of 2006, the mutual funds replaced their group affiliation from winners to losers, and from losers to winners in consecutive periods. Unfortunately, it is impossible to explain the occurrence of performance reversal in 2003 in a similar way. Furthermore, the consequences of financial crisis visible from the second half of 2007 were generally unfavourable as far as the phenomenon of performance persistence is concerned.

\section{Conclusions}

The main aim of this paper was to examine if the performance of mutual funds in Hungary is characterised by persistence. The short-term performance persistence was confirmed in all the tests and through the application of both the measures, i.e. the rate of return and the Sharpe index. Such a result can undoubtedly be important and useful to the investors while allo- cating assets. Furthermore, the occurrence of performance persistence enables market participants to draw additional conclusions related to the evaluation of organisational solutions applied by the mutual funds in Hungary.

The 1-year persistence was not such unequivocal as the 6-month persistence. Within the longer horizon, the results often depended on the applied measures of performance. Additionally, the author's intension was to indirectly specify the causes of performance persistence. Since the estimated Jensen's alphas, that could explain performance persistence by managerial skills, were insignificant, I was able to examine only the dependence of performance upon the market situation. This relationship was partly confirmed by the occurrence of the performance persistence periods with the periods of well-defined tendencies on the Budapest Stock Exchange and the periods of performance reversal with the periods of significant changes in market trends illustrated by values of the BUX.

In general, the results of the research concerning mutual fund performance in Hungary fit the previous findings discussed in the finance literature. The obtained evidence of the occurrence of performance persistence correspond also well with the sparse findings made in other CEE countries. The results of the methodologically similar Hungarian and Polish research (cf. Jackowicz \& Filip, 2009) lead to convergent conclusions about the strength of performance persistence phenomena, especially in short periods. However, as far as the results of the Hungarian research are concerned, they are not method-dependent.

The phenomenon of performance persistence in the $\mathrm{CEE}$ countries is rarely investigated. Hence, this paper is an attempt to fill the existing research gap. Furthermore, a number of research methods were used for the sake of the study. The estimation of the stochastic kernel as a research method gives us a new outlook on the examination of the performance persistence phenomenon. Even though the supplied data contained survivorship bias, the presented results concerning performance persistence of equity funds may serve as a basis for further research provided that there will be an increase in the number of mutual funds in Hungary and that the data will include the non-existent companies. Moreover, the research discussed in the present paper may lay the foundations for analysing 
performance of other forms of collective investment companies in Hungary.

\section{References}

1. Berger, A.N., Bonime, S.D., Covitz, D.M., \& Hancock, D. (2000). Why are bank profits so persistent? The roles of product market competition, informational opacity, and regional macroeconomic shocks. Journal of Banking and Finance, 24(7): 1203-1235.

2. Blake, C.R., Elton, E.J., \& Gruber, M.J. (1993). The performance of bond mutual funds. The Journal of Business, 66(3): 371-403.

3. Bollen, N.P. \& Busse, J.A. (2005). Short-term persistence in mutual fund performance. Review of Financial Studies, 18(2): 569-597.

4. Brown, S.J. \& Goetzmann, W.N. (1995). Performance persistence. The Journal of Finance, 50(2): 679-698.

5. Brown, S., Goetzmann, W., Ibbotson, R., \& Ross, S. (1992). Survivorship bias in performance studies. Review of Financial Studies, 5(4): 553-580.

6. Capocci, D. \& Hubner, G. (2004). Analysis of hedge fund performance. Journal of Empirical Finance, 11(1): 55-89.

7. Carhart, M. (1997) On persistence in mutual fund performance. The Journal of Finance, 52(1): 5782.

8. Casarin, R., Lazzarin, M., \& Sartore, D. (2002). Performance, Style and Persistence of Italian Equity Funds. Working Papers. April 9, 2002 GRETA, Venice.

9. Chevalier, J. \& Ellison, G. (1999). Are some mutual fund managers better than others? Crosssectional patterns in behaviour and performance. Journal of Finance 54(3): 875-899.

10. Collinet, L. \& Firer, C. (2003). Characterising persistence of performance amongst South African general equity unit trusts. Omega, 31(6): 523 538.

11. Cuthbertson, K., Nitzsche D., \& O’Sullivan, N. (2008). UK mutual fund performance: Skill or luck? Journal of Empirical Finance, 15(4): 613-634.

12. Dahlquist, M., Engstrom, S., \& Soderlind, P. (2000). Performance and characteristics of Swedish mutual funds. Journal of Financial and Quantitative Analysis, 35(3): 409-423.
13. Droms, W.G. \& Walker, D.A. (2001). Performance persistence of international mutual funds. Global Finance Journal, 12(2): 237-248.

14. Du, D., Huang, Z., \& Blanchfield, P.J. (2009). Do fixed income mutual fund managers have managerial skills? The Quarterly Review of Economics and Finance, 49(2): 378-397.

15. Durlauf, S.N. \& Quah, D.T. (1998). The new empirics of economic growth. NBER Working Papers Series, No. 6422.

16. Elton, E.J., Gruber, M.J., \& Blake, C.R. (1996). The persistence of risk-adjusted mutual fund performance. Journal of Business, 69(2): 133-157.

17. Epstein, P., Howlett, P., \& Schulze, M.-S. (2000). Distribution dynamics: Stratification, polarisation, and convergence among OECD economies, 1870-1992, London School of Economics, Working Paper No. 58.

18. Erdõs, P. \& Ormos, M. (2009) Return calculation methodology: Evidence from the Hungarian mutual fund industry. Acta Oeconomica, 59(4): 391-409.

19. Fama, E.F. \& French, K.R. (1993). Common risk factors in the returns on stocks and bonds. Journal of Financial Economics, 33(1): 3-56.

20. Ferson, W. \& Schadt, R. (1996). Measuring fund strategy and performance in changing economic conditions. Journal of Finance, 51(2): 425-462.

21. Fletcher, J. \& Forbes, D. (2002). An exploration of the persistence of UK unit trust performance. Journal of Empirical Finance, 9(5): 475- 493.

22. Grinblatt, M. \& Titman, S. (1989). Mutual fund performance: An analysis of quarterly portfolio holdings. The Journal of Business, 62(3): 393-416.

23. Grinblatt, M. \& Titman, S. (1992). The persistence of mutual fund performance. Journal of Finance, 47(5): 1977-1984.

24. Goetzmann, W.N. \& Ibbotson, R.G. (1994). Do winners repeat? The Journal of Portfolio Management, 20(2): 9-18.

25. Hallahan, T.A. (1999). The information content of portfolio performance history and persistence in fund performance: An examination of rollover funds. Accounting and Finance, 39(3): 255-274.

26. Hendricks, D., Patel, J. \& Zeckhauser, R. (1993). Hot hands in mutual funds: short-run persistence of relative performance, 1974-1988. Journal of Finance, 48(1): 93-130. 
27. Hyndman, R.J., Bashtannyk, D.M. \& Grunwald, G.K. (1996) Estimating and visualising conditional densities. Journal of Computational and Graphical Statistics, 5(4): 315-336.

28. Ippolito, R.A. (1992). Consumer reaction to measures of poor quality: Evidence from the mutual fund industry. Journal of Law and Economics, 35(1): 45-70.

29. Jackowicz, K. (2008). Performance persistence of banking sector in Poland. In: Nowak, A.Z. and Glinka, B. (Eds.): Management Qualitative and Quantitative Research. Warsaw: Wydawnictwo Naukowe Wydziału Zarządzania Uniwersytetu Warszawskiego, pp. 118-128.

30. Jackowicz, K. (2009). Determinants of winning and losing persistence in the Polish banking sector. Bank and Credit, 40(3): 5-23.

31. Jackowicz, K. \& Filip, D. (2009). Powtarzalność wyników funduszy inwestycyjnych w Polsce [The persistence of mutual fund performance in Poland]. Materiały i Studia No. 236. Warsaw. NBP.

32. Jackowicz, K. \& Kozłowski, Ł. (2008). Analiza dynamiki rozkładów rentowności banków komercyjnych w Polsce z użyciem jądra stochastycznego [Dynamics of profitability distribution: an analysis of commercial banks in Poland with the application of stochastic kernel]. In: Współczesne finanse. Stan i perspektywy rozwoju bankowości. Toruń: Wydawnictwo Naukowe UMK, pp. 325-334.

33. Jensen, M. (1968). The performance of mutual funds in the period 1945-1964. Journal of Finance, 23(1): 389-416.

34. Kanji, G.K. (2006). 100 Statistical Tests. SAGE Publications Ltd. London, Thousand Oaks, New Delhi, third edition.

35. Kulczycki, P. (2008). Applicational possibilities of non-parametric estimation of distribution density for control engineering. Bulletin of the Polish Academy of Sciences: Technical Sciences 56(4): 347-359

36. Malkiel, B.G. (1995). Returns from investing in equity mutual funds 1971 to 1991 . The Journal of Finance, 50(2): 549-572.

37. Mayo, H.B. (1997). Investment: An Introduction. 5th ed.: The Dryden Press

38. Otten, R. \& Bams, D. (2002). European mutual fund performance. European Financial Management, 8(1): 75-101.
39. Philpot, J., Hearth, D., Rimbey, J.N., \& Schulman, C.T. (1998). Active management, fund size, and bond mutual fund returns. The Financial Review, 33(1): 115-126.

40. Sandvall, T.C.H. (2000). Performance persistence: New evidence for the Finnish mutual fund market. The Finnish Journal of Business Economics, LTA 1/00: $71-85$.

41. Silva, F., Cortez, M.C., \& Armada M.R (2005). The persistence of European bond fund performance: Does conditioning information matter? International Journal of Business, 10(4): 341-361.

42. Sharpe, W.F. (1966). Mutual funds performance. Journal of Business, 39(1): 119-138.

43. Sharpe, W.F. (1994). The Sharpe ratio. Journal of Portfolio Management, 21(1): 49-58.

44. Tonks, I. (2005). Performance persistence of pension fund managers. The Journal of Business, 78(5): 1917-1942

45. Treynor, J. (1965). How to rate management of investment funds. Harvard Business Review, 44(1): 63-75.

46. Westlake, W.J. (1971). A one-sided version of the Tukey-Duckworth test. Technometrics 13(4): 901 903. 